\title{
The Development of Subjective Checklist Measuring Change in Global Cognition
}

\author{
Eunkyung Jeong, JungWan Kim \\ Department of Speech Pathology, College of Rehabilitation Sciences, Daegu University, Gyeongsan, Korea
}

\author{
Received: May 8, 2020 \\ Revised: June 8, 2020 \\ Accepted: June 25, 2020 \\ Correspondence: \\ JungWan Kim, PhD \\ Department of Speech Pathology, \\ College of Rehabilitation Sciences \\ Daegu University, \\ 201 Daegudae-ro, Jillyang-eup, \\ Gyeongsan 38453, Korea \\ Tel: +82-53-850-4325 \\ Fax: +82-53-850-4329 \\ E-mail: kimjungwan@daegu.ac.kr
}

\begin{abstract}
Purpose: There is enough evidence to support an informant based survey in screening efforts for the identification of cases of cognitive changes in community dwelling elderly. Therefore, this study focused on items affecting daily living activities more among the cognitive abilities in the elderly. Methods: The main focus of the current study was to assess the feasibility, reliability, and validity of a subjective checklist measuring change in global cognition (SCC-GC) for differentiation of subjects with memory impairment from community dwelling elderly. A total of 61 elderly individuals were administered a newly developed SCC-GC in order to determine its utility in measuring cognitive changes in the elderly. Results: SCC-GC consists of 1-3 questions in each of six sub-domains: subjective competence of cognition and language (1 item), reading and writing (2 items), usage and learning of internet (3 items), familiar daily activity (3 items), drinking alcohol (1 item), TV comprehension ( 1 item). Factor analysis indicated the total score of SCC-GC correlated with depression, memory and mental status. Also, we found that the difference in the total score of the SCC-GC has a significant difference between the groups. Conclusion: Through this study, it is expected that the cognitive changes can be easily checked by using their own daily life patterns and used periodically to help prevent cognitive impairment and dementia.
\end{abstract}

Key Words: Amnestic mild cognitive impairment, Cognition, Elderly, Subjective checklist.

\section{INTRODUCTION}

경도인지장애(mild cognitive impairment, $\mathrm{MCI}$ )는 인지기능 의 저하가 정상범위를 벗어나지만 아직 치매로 진단할 수 있을 정도로는 심하지 않은 상태를 의미한다. 임상적 진단 기준에 의 하면, $\mathrm{MCI}$ 진단에 경미한 기억력 손상부터 일부 초기의 치매 환자들이 포함되어 집단 내에서도 양상과 경과가 이질적이고 중복되어 나타난다(Petersen et al., 2001). MCI에 대한 연구가 깊이 있게 진행되면서 여러 가지 아형들(subtypes)이 존재하는 것이 확인되었는데(Petersen, 2003), 기억장애 유무와 손상받 은 영역의 개수에 따라 기억성(amnestic) $\mathrm{MCI}$ (aMCI), 다영역 $\mathrm{MCI}$, 비기억성 단일 영역 $\mathrm{MCI}$ 로 분류하고 있다. 이 중에서도 많은 연구가 진행되고 있는 $\mathrm{aMCI}$ 의 경우 퇴행성 질환의 초기 상태로 간주되며, 시간이 지나면서 알츠하이머병(Alzheimer's disease, $\mathrm{AD}$ ) 치매로 발전할 가능성이 높은 것으로 보고 있다.

(c) This is an Open Access article distributed under the terms of the Creative Commons Attribution Non-Commercial License (https://creativecommons.org/licenses/by-nc/4.0) which permits unrestricted non-commercial use, distribution, and reproduction in any medium, provided the original work is properly cited.
따라서 최근에는 알츠하이머병에 기인한 경도인지장애라는 용 어를 사용하기도 한다(Korea Dementia Association, 2011). $\mathrm{aMCI}$ 를 진단하기 위해서는 1) 환자 및 보호자에 의한 주관적 기억장애에 대한 호소가 있고, 2) 신경심리검사상 기억 영역에 서 나타나는 객관적인 인지기능 저하가 있으며, 3) 기억 영역을 제외한 전반적인 인지기능이 정상이고, 4) 일상생활 수행능력이 정상이고, 5) 치매로 진단되지 않아야만 한다(Petersen, 2004). $\mathrm{aMCI}$ 의 진단 기준을 사용할 경우 매년 10 15\%의 $\mathrm{MCI}$ 환자가 치매로 진행하게 되는데, 정상 노인들의 $1 \sim 2 \%$ 만이 매년 치매로 진행하는 것에 비하면 매우 높은 수준을 상회한다(Petersen et al., 2001).

대부분의 임상에서 인지장애는 객관적인 인지검사를 통해 평가된다(Galvin et al., 2006). 그러나 한 가지 검사로 여러 아 형을 포함하고 있는 $\mathrm{MCI}$ 를 진단할 수 있는 신경심리검사 항목 이나 도구는 없고, Diagnostic and statistical manual of mental disorders, fifth edition (American Psychiatric Aoociation, 2013)이나 National Institute of Neurological and Communicative Disorders and Stroke/Alzheimer's Disease and 
Related Disorders Association (McKhann et al., 1984) 진단 기준을 참고하여 일차적으로는 의사의 경험에 의한 임상적 진 단을 해야 한다. 인지적 변화를 평가하는 방식은 결함이 나타 나는 양상을 파악하고 중증도를 예측하기 위해 임상가가 대상 자에게 직접 실시해 보는 객관적 평가도 있지만, 비임상 현장에 서 일상의 기능적인 측면을 반영하고(Buelow et al., 2014) 일상 생활의 인지-언어적 양상이나 장기간에 걸친 연속적인 변화를 (Gavett et al., 2011) 정보 제공자 보고를 통해 평정하는 주관적 평가도 있다. 특히 정보 제공자 보고형 평가의 신뢰도와 효용성 은 자가보고의 신뢰도가 감소되어 있는 중증 치매 환자에게서 유리한 것으로 언급되지만(Clare et al., 2011), MCI 환자에게서 도 전반적인 인지능력에 대한 정보 제공자 평가와 객관적인 신 경심리검사 결과 간에 상관성이 높고(Lee, 2015) MCI 변별에 있 어서도 유용하다는 보고가 있다(Fyock \& Hampstead, 2015). 이처럼 여러 연구들을 통해 초기의 인지 변화는 정보 제공자 기 반 평가나 설문지를 통해 파악하는 것이 더 변별력이 높고 민감 한 것으로 알려져 왔다(Isella et al., 2006; Storandt et al., 2006).

인지장애에 대한 지역사회 기반 선별은 인지 저하의 초기 상 태에 있는 노인을 선별하고(Schinka et al., 2009) 지속적으로 관리하는 데 있다. 대단위 지역사회 조사는 대부분 설문을 통 해 이루어지기 때문에 사실상 객관적인 인지검사보다는 정보 제공자 기반 평가나 설문지를 통한 경우가 많다. 이처럼 선별 및 진단을 위한 정보 제공자 기반 접근 방식이 갖는 유용성이 입증 되어 왔음에도 불구하고, $\mathrm{MCI}$ 와 같이 인지 저하의 초기 상태에 있는 노인의 인지기능을 특징적으로 다룬 평가 도구나 설문지 는 흔하지 않다. 특히 $\mathrm{aMCI}$ 는 다른 인지기능이나 도구적 일상 생활, 일화 기억 등이 보존되므로(Schinka et al., 2009), 치매에 초점을 맞춘 항목보다는 $\mathrm{aMCI}$ 의 전반적인 인지에 초점을 두고 이에 영향을 받는 하위 영역들을 살펴보고 이 중 가장 영향력이 있는 변수들을 선별한다면, 노화 과정에서 $\mathrm{aMCI}$ 를 발견하고 그 들의 인지 변화를 추적할 때 유용하게 활용할 수 있을 것이다.

기존에 인지 변화를 선별할 수 있는 목적으로 설계된 정보 제공자 기반 척도는 여러 가지가 있다. 그중 cognitive change checklist (Schinka et al., 2009), informant questionnaire on cognitive decline in the elderly (Jorm, 1994), everyday cognition (Farias et al., 2008)과 같은 대표적인 척도의 제한점을 열거하면 다음과 같다. 첫째, 앞서 언급한 도구들은 주로 치매 에 초점을 두고 문항이 구성되어 있어(Schinka et al., 2009) 아 직 $\mathrm{MCI}$ 에게서는 잘 관찰되지 않는 행동 양상들이 좀 더 많은 편이다. 가령 언어, 지연 회상, 일화기억, 집행기능에 초점을 두 고 작성된 항목들은 ‘약속을 잊은 적이 있습니까?', ‘당신의 기 억이나 일상 속의 사고에 어려움을 겪은 적이 있습니까?'와 같 이 일반적으로 치매선별검사에서 빈번히 이루어지는 질문 위주
로 구성되어 인지 변화를 측정하는 기간이 길기 때문에 짧은 기 간 내에서의 행동 변화량, 즉 $\mathrm{MCI}$ 의 일상 속 인지 변화를 촘촘 하게 포착하기가 어려울 수도 있다. 둘째, 정보 제공자 기반 척도 라는 점에서 검사 실시 방법은 동일하더라도 일상 속의 인지능 력을 정례적으로 파악하기 위한 목적보다는 인지장애를 감별하 기 위한 '검사'로서의 성격이 두드러진다. 즉, 일상 속의 인지를 파악하는 성격보다는 노인의 인지 저하를 감별해 내고 $\mathrm{MCI}$ 에 서 치매로 진행될 위험이 높은 노인을 감별해 내기 위한 목적 으로 개발되어 인지감별검사로서의 간이정신상태검사(minimental status examination, MMSE)의 성격과 비슷한 척도들이 주를 이룬다고 볼 수 있다. 셋째, 문항에 따라서는 정보 제공자 의 숙련도에 따라(예: 간호사, 작업치료사, 언어재활사 등의 간 호보건 인력 VS. 가족, 간병인 등의 일반 인력) 반응을 다르게 매길 수 있는 것들도 존재하는 등 내용 구성에 있어 재고해야 할 측면이 있다. 가령 일상생활 패턴(예: TV 이해, 외출 정도, 알코올 섭취량)과 관련된 항목은 간호보건 인력 외에도 비전문 가인 조사자들도 평가가 가능하지만, 기존의 척도들은 기억력, 언어, 시공간 인지능력, 계획하기, 지남력과 분리적 주의집중력 의 저하로 인해 일상생활에서 경험하게 되는 어려움을 예로 들 되 일상생활 활동(activities of daily living)처럼 기능상의 어 려움(예: 적은 개수의 장보기 항목 기억하기, 대화 회상하기 등) 에 좀 더 초점을 두고 있어 누구나 쉽게 실시할 수 있는 성격을 갖고 있지는 않다.

정상적인 노화 과정에서 인지장애 환자를 분리해 내기 위한 정보 제공자 기반 평가 척도는 객관적인 인지검사에서 실시하 는 작업 유형을 취하는 것보다는 쉽고 간편하게 묻고 반응을 얻을 수 있는 형태를 갖추는 것이 좋을 것이다. 또한 인지 저하 를 경험하고 있다면, 정보 제공자가 노인 스스로인 것보다는 노 인을 주로 돌보는 주 보호자가 되는 것이 더욱 신뢰로운 반응 을 얻을 수 있다. 따라서 '예전보다 잘 기억이 나지 않아 불편합 니까?', ‘약속을 자주 잊으십니까?'와 같이 질적 자료의 성향이 다소 강한 문항보다는, '일주일에 술을 마시는 양', '새로운 정보 를 학습하는 빈도' 등과 같이 좀 더 정량적 평가가 가능한 문항 위주로 구성하는 것이 신뢰로운 평가를 유도할 것이다.

인지능력에 영향을 미치는 변수들을 조사한 연구들을 살펴 보면 연령, 교육 연수, 성별, 배우자와의 동거 유무, 음주 유무, 일상생활 독립성 등이 인지능력과 상관관계를 가지며, 운동, 사 회적 활동, 인지 자극 활동 등은 치매 발병을 지연시키는 것으 로 보고하고 있다(Fratiglioni et al., 2004; Paillard-Borg et al., 2012). 따라서 노인군 내에서 기억장애 고위험군을 변별하 고 지속적으로 추적관찰하기 위해서는 인지능력과 영향을 주 고 받는 일상생활 활동 정도와 변화량을 파악할 수 있는 체크 리스트의 개발이 필요하다. 
현재 국내에는 노인 인지-언어능력의 객관적 평가를 보완하 면서 진단적 정확도를 높이는 데 활용할 수 있는 노년기 인지언어능력에 대한 정보 제공자 보고형 평가 척도(informant-report scale on cognitive-linguistic abilities of the elderly) (Lee $\&$ Kim, 2020)가 있으며, 이 도구에서는 주의력, 시공간력, 기억 력, 고차원 인지의 4개 하위 영역과 이해, 표현, 읽기 및 쓰기, 화 용언어의 4 개 하위 영역을 통해 얻게 된 주관적 평가 결과가 객 관적인 인지-언어검사상 수행과 상관성을 보임을 언급하였다. 이 도구의 경우 정상 노인군과 경도인지장애군, 치매군에게까 지 진단적 변별도가 높은 문항들로 구성되어 있어 인지장애 환 자가 경험할 수 있는 하위 인지 영역들 위주로 문항이 구성되 어 있다. 따라서 상세한 인지 및 언어 영역별 수행에 대한 보호 자의 주관적 보고와 함께 쓰일 수 있는 일상생활의 활동과 변 화 정도에 대한 주관적 체크리스트도 마련된다면 인지장애 유 무와 정도를 판별하기 위한 주관적 평가 도구의 신뢰도를 높이 는 데 기여할 수 있을 것이다. 특히, aMCI는 인지를 향상시킬 수 있는 어떠한 약물치료는 없는 반면, 질병의 진행 정도가 느리고 (Cooper et al., 2013) 뇌의 가소성이 높다는 점에서(Belleville et al., 2011; Paillard-Borg et al., 2012) 행동 중재 전략을 적용 하기 가장 좋은 집단으로 간주된다. 따라서 $\mathrm{aMCI}$ 의 전반적 인 지능력의 변화를 지속적으로 살펴보는 것은 이 집단이 치매로 진행되는 양상과 속도를 파악하고, 관리해야 할 영역을 발견하 는 데 도움을 줄 것이다.

본 연구에서는 일상생활에서의 활동과 변화 정도를 간단하 면서도 신뢰롭게 파악하여 노인의 전반적인 인지능력의 변화 를 추적할 수 있는 체크리스트 예비본을 구축하고, 실제 피험 자의 주관적 설문을 통해 인지능력과 상관성이 높은 변수들을 추출한 후 언제 어디서든 간호, 보건, 복지 전문가에 의한 일상 적 평가가 가능할 수 있도록 전반적 인지 변화를 측정하는 주 관적 체크리스트(subjective checklist measuring change in global cognition, $\mathrm{SCC}-\mathrm{GC}$ )의 예비 모델을 제작하였다. 이를 통해 전 임상 단계에서 의료기관에 내원한 경험은 아직 없지만 인지장애 고위험군을 조기에 선별해 내거나 그 이후의 인지 변 화를 주기적으로 체크할 수 있는 데 도움을 주고자 하였다.

\section{MATERIALS AND METHODS}

\section{연구 대상}

27명의 aMCI와 34명의 일반 노인(elderly without cognitive impairment, ECI)을 포함한 총 61명의 지역사회 노인들을 대 상으로 2018년 8 11월까지 예비적으로 개발된 SCC-GC를 적용 하였다. 일반 노인군은 65 세 이상으로 한국판 간이정신상태검사 (Korean-mini mental status examination, K-MMSE) (Kang,
2006) 및 서울 구어학습검사(Seoul verbal learning test, SVLT) (Kang \& Na, 2003)에서 정상 범위(16\%ile 이상)에 속하고, Christensen et al.(1991)의 건강선별설문지 실시 결과 신경정신 학적 병력이 없는 자를 대상으로 하였다. $\mathrm{aMCI}$ 군은 신경과 전 문의에 의해 진단된 자로, 단축형 노인우울검사(short version of the geriatric depression scale, SGDS) (Jung et al., 1997)의 점수가 8점 미만으로 정상 범위에 속하고, 한국판 도구적 일상 생활척도(Korean-instrumental activities of daily living) (Won et al., 2002) 점수가 0.43점 미만으로 일상생활의 어려움 이 없으며, 임상치매평정(clinical dementia rating) (Hughes et al., 1982)에서 0.5점으로 치매 의심군에 해당되는 자를 대상으로 하였다.

\section{연구 절차}

\section{예비 체크리스트 고안}

본 연구에 필요한 체크리스트 작성을 위한 문헌 검색은 학술 연구정보서비스(RISS), 한국학술정보(Korean Studies Information Service System, KISS), DBpia 등의 데이터베이스를 사용하였다. 한국어 검색어는 '인지기능/인지능력, '초기치매/경 도인지장애', '여가활동/사회활동', 그리고 '신체활동/운동' 등으 로 검색하였으며, 영어 검색어는 'cognitive function/cognitive ability', 'early dementia/mild cognitive impairment', 'leisure activity/social activity', 그리고 'physical activity/exercise' 등 으로 검색하였다. 경증 치매나 $\mathrm{aMCI}$ 를 대상으로 한 연구, 인지 에 영향을 미치는 변인에 대한 연구와 전문을 획득할 수 있는 경우를 포함시키고, 중복 자료, 한국어와 영어를 제외한 언어로 작성된 논문과 본 연구의 선정 기준과 부합되지 않는 연구는 제외하였다. 선정한 논문들의 결과를 종합하여 체크리스트 고 안에 필요한 내용을 정리하였고, 경력 10년 이상의 언어병리학 자 1 인, 언어병리학 박사학위 소지자 1 인, 그리고 연구자들 간 의 의견 교환을 통해 노인의 인지능력에 영향을 미칠 것으로 예상되는 일상생활 활동 내용을 추가적으로 선정하여 체크리 스트에 포함시켰다. 이러한 과정을 통해 완성된 예비 체크리스 트의 예는 Figure 1과 같다.

\section{예비 조사}

본 실험에 앞서 체크리스트에 대한 명시성, 가독성, 해석의 중의성, 반복성 등을 확인하기 위하여 2급 이상의 언어재활사 자격을 소지한 20 30대 건강한 성인 15명을 대상으로 예비 실험을 실시하였다(평균연령: $25.8 \pm 2.2$ 세, 평균 교육 연수: $16.4 \pm 0.8$ 년, 남:여 = 2:13). 예비 실험 결과 대상자들은 가독 성의 문제로 도표 수정이 필요하다고 언급하였고, 명시성의 문 


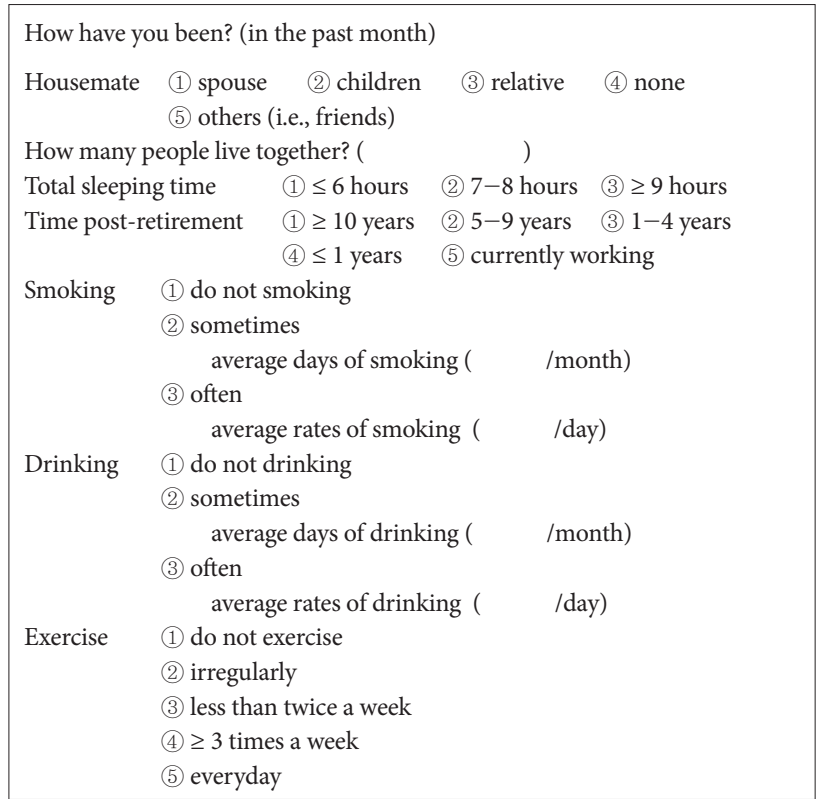

Figure 1. Example of survey item for pilot study.

제로 어휘 수정이 필요하다는 반응을 보였다. 따라서 본 실험에 서는 가독성을 높이기 위해 글자의 크기와 도표를 수정하고, 노 인들이 어렵다고 느낄 수 있는 단어를 수정하여 좀 더 편하게 이해하고 답할 수 있도록 하였다. 또한 본 실험 시 조용한 공간 을 확보하고, 1 대 1 의 상황을 유지하여 충분한 설명과 예시 문 항이 함께 제공될 수 있도록 하였다.

\section{본 조사}

설문은 소음이 통제된 곳에서 27 명의 $\mathrm{aMCI}$ 와 34 명의 $\mathrm{ECI}$ 를 대상으로 실시되었고, 대상자와 검사자가 1 대 1 상황에서 작성 된 질문을 함께 읽고, 체크리스트의 각 항목에 평정하는 방식 으로 실시하였다. 본 실험을 시작하기 전 연구자는 대상자에게 체크리스트의 항목이 일상생활과 관련된 여러 가지 질문들이 포함되어 있음을 알려주고, 연습 문항을 예로 들며 설명하였다.

\section{통계 분석}

두 집단의 동질성 검증을 위해 $t$ 검정을 실시하였다. 인지능력 에 영향을 미치는 변인들을 파악하기 위해, 탐색적 요인 분석 을 통해 몇 개의 요인으로 묶이는지 확인한 후, 요인 내 포함된 변수들을 단계적으로 투입한 다중회귀분석을 실시하였다. 인 지능력에 영향을 미치는 유효 변수의 $\beta$ 값을 이용하여 가중치 를 산정하였고, 이 변수들이 포함된 SCC-GC의 최종본을 작성 한 후 재코딩된 두 군의 체크리스트 총점과 하위 영역별 평균 점수를 $t$ 검정을 사용하여 비교, 제시하였다. 인지장애 유무를 변별해 주는 진단적 절단점 산정을 위해 receiver operating characteristic (ROC) 분석을 실시하였다. 전체 피험자의 $20 \%$
Table 1. Demographic information of participants

\begin{tabular}{lrrr}
\hline \multicolumn{1}{c}{ Variables } & ECI $(\mathrm{n}=34)$ & aMCI $(\mathrm{n}=27)$ & \multicolumn{1}{c}{$t$} \\
\hline Age (yr) & $76.38(6.94)$ & $78.56(5.04)$ & -1.415 \\
Level of education (yr) & $7.06(5.22)$ & $7.48(4.46)$ & -0.335 \\
K-MMSE & $26.12(3.39)$ & $22.11(4.07)$ & $4.194^{* * *}$ \\
SGDS & $1.47(1.66)$ & $3.67(2.22)$ & $0.233^{* * *}$ \\
SVLT-E & $16.35(3.64)$ & $9.56(2.52)$ & $0.302^{* * *}$ \\
\hline
\end{tabular}

${ }^{* * *} p<0.001$. ECI: elderly without cognitive impairment, aMCI: amnestic mild cognitive impairment, K-MMSE: Korean-mini mental status examination, SGDS: short version of the geriatric depression scale, SVLT-E: Seoul verbal learning test-elderly's version

에게는 2주 간격을 두고 $\mathrm{SCC}-\mathrm{GC}$ 를 실시함으로써 검사-재검 사 신뢰도를 파악하였다. 또한 SCC-GC 검사 결과와 기본 검 사[예: SVLT-elderly's version (SVLT-E), K-MMSE, SGDS] 수행력 간의 Pearson 상관분석을 통해 전반적인 인지 변화에 대한 주관적 보고와 객관적인 인지 능력 및 우울감 간에 어느 정도의 상관성을 보이는지 알아보았다. 통계 프로그램은 SPSS 22.0(IBM Corp., Armonk, NY, USA)을 사용하였다.

\section{RESULTS}

\section{두 집단의 동질성 검정 결과}

$\mathrm{aMCI}$ 군과 $\mathrm{ECI}$ 군의 동일성 검정 결과 연령 $(t=-1.415, p=$ $0.162)$ 및 교육 연수 $(t=-0.335, p=0.739)$ 에서 유의한 차이가 없 었으며, K-MMSE ( $t=4.194, p<0.001)$, SGDS $(t=0.233, p<$ $0.001)$, SVLT-E $(t=0.302, p<0.001)$ 에 대한 두 집단 간 차이 의 유의성을 확인한 $t$-test 결과는 Table 1에 제시하였다.

\section{요인 분석 결과 및 척도 특성}

직교(베리맥스) 회전 및 사각 회전 방식을 적용한 주 성분 분 석 및 주축 분해법을 이용한 탐색적 데이터 감소 분석을 실시 하였다. 요인 분석 결과 eigenvalues가 1 이상이면서 가장 높은 eigenvalues를 기준으로 하였을 때 총 6개의 요인이 추출되었 다. 각 변수와 요인 간의 상관계수를 의미하는 회전 적재량은 (Song, 2015) 0.40을 초과하여 해당 변수들이 이 요인으로 잘 설명될 수 있음을 확인하였다. 요인 1은 가계 관리, 식사 준비, 필수품 구매 변수가 포함되는 '집안일', 요인 2는 인터넷 사용, 인터넷 문자, 배움 변수가 포함되는 '인터넷 사용과 배움, 요인 3 은 사회적 활동, 익숙한 활동, 약 복용과 교통수단 및 전화 사 용 변수가 포함되는 '익숙한 일', 요인 4는 정보 읽기와 일정 정 리 변수가 포함되는 '읽기/쓰기', 요인 5는 의사소통 시간과 빈 도 변수가 포함되는 '의사소통', 요인 6은 여가활동과 운동 시간 변수가 포함되는 '여가활동’으로 6가지의 요인에 각각의 요인명 을 부여하여 구분하였다. 
Table 2. Results of multiple regression analysis on the factors of everyday living influencing cognitive ability

\begin{tabular}{|c|c|c|c|c|c|c|}
\hline \multirow{2}{*}{ Factors } & \multicolumn{2}{|c|}{ Unstandardized coefficients } & \multirow{2}{*}{$\begin{array}{c}\text { Standardized coefficients } \\
\beta\end{array}$} & \multirow{2}{*}{$t$} & \multicolumn{2}{|c|}{ Collinearity } \\
\hline & $\mathrm{B}$ & SE & & & Tolerance & VIF \\
\hline (Constant) & 19.878 & 3.626 & - & $5.482^{* * *}$ & - & - \\
\hline SCL & 0.619 & 0.192 & 0.300 & $3.234^{* *}$ & 0.896 & 1.116 \\
\hline $\mathrm{R} \& \mathrm{~W}$ & 1.436 & 0.449 & 0.302 & $3.198^{* *}$ & 0.861 & 1.161 \\
\hline ULI & 1.171 & 0.425 & 0.246 & $2.752^{* *}$ & 0.959 & 1.042 \\
\hline FDA & 1.129 & 0.420 & 0.238 & $2.690^{* *}$ & 0.986 & 1.015 \\
\hline DA & -2.060 & 0.846 & -0.219 & $-2.436^{*}$ & 0.949 & 1.053 \\
\hline TVcom & 1.140 & 0.522 & 0.198 & $2.185^{*}$ & 0.939 & 1.065 \\
\hline
\end{tabular}

${ }^{*} p<0.05,{ }^{* *} p<0.01,{ }^{* * *} p<0.001$. SE: standard error, VIF: variance inflation factor, SCL: subjective competence of cognition and language, R\&W: reading and writing, ULI: usage and learning of internet, FDA: familiar daily activity, DA: drinking alcohol, TVcom: TV comprehension, Adj: adjusted

요인 분석에서 제거된 문항이지만 추가적으로 유의하다고 생 각되는 3 개의 문항(예: TV 이해, 주관적 인지 및 언어능력 등) 을 연구자들이 논의하여 포함시킨 후 단계적 다중회귀분석을 실시하였다. 그 결과(Table 2), K-MMSE를 통해 파악한 전반적 인 인지 상태는 '주관적 인지 및 언어 $(t=3.234, p<0.01)$, '읽기/ 쓰기 $(t=3.198, p<0.01)$ ', '인터넷 사용과 배움 $(t=2.752, p<$ $0.01)$ ', '익숙한 일 $(t=2.690, p<0.01)$ ', '음주 $(t=-2.436, p<$ $0.05)$,' 'TV 이해 $(t=2.185, p<0.05)$ '의 영향을 받는 것으로 나 타났고, 이때 설명력은 $50.8 \%$ 로서 회귀식은 다음과 같다.

$$
\begin{aligned}
y= & a+b 1 \times 1+b 2 \times 2+b 3 \times 3+b 4 \times 4+b 5 \times 5+ \\
& b 6 \times 6
\end{aligned}
$$

$y=19.878+0.619$ (subjective competence of cognition and language) +1.436 (reading and writing) +1.171 (usage and learning of internet $)+1.129$ (familiar daily activity) 2.060 (drinking alcohol) +1.140 (TV comprehension)

$\mathrm{SCC}-\mathrm{GC}$ 총점과 하위 요소(= 영역) 간의 coefficients alpha 는 0.691로 acceptable 수준이었다. 표준화계수 베타( $\beta$ ) 값을 통 해 각 요인들의 상대적인 영향력을 비교한 결과 ‘음주', '읽기/쓰 기', ‘인터넷 사용과 배움, 'TV 이해', '익숙한 일' 순으로 전반적 인 인지능력에 미치는 영향력이 큰 것으로 나타났다.

회귀 분석 결과의 $\beta$ 값을 이용하여 각 하위 요소의 상대적 영향력을 확인한 후 총점을 100점으로 한 하위 요소 내 개별 문항들의 점수를 산정하였다. SCC-GC는 6개의 하위 요소로 구성되며 총 11 개의 문항이 포함되었고 점수 범위는 11 100점 이다: 주관적 인지 및 언어능력(1문항, 점수 범위: 0 20), 읽기 및 쓰기(2문항, 점수 범위: 4 20), 인터넷 사용과 배움(3문항, 점수 범위: 2 16), 익숙한 일(3문항, 점수 범위: 3 16), 음주(1문 항, 점수 범위: 1 15), TV 이해(1문항, 점수 범위: 1 13). 이 척도
Table 3. Total score and sub-item scores of subjective checklist measuring change in global cognition between $\mathrm{ECl}$ and $\mathrm{aMCl}$ groups

\begin{tabular}{lccc}
\hline \multicolumn{1}{c}{ Items } & ECI $(\mathrm{n}=34)$ & $\mathrm{aMCI}(\mathrm{n}=27)$ & $t$ \\
\hline Total score & $66.32( \pm 12.00)$ & $58.19( \pm 11.93)$ & $2.637^{*}$ \\
SCL & $13.24( \pm 5.21)$ & $11.48( \pm 5.34)$ & 1.292 \\
R\&W & $10.59( \pm 4.89)$ & $8.59( \pm 4.25)$ & 1.676 \\
ULI & $5.47( \pm 4.71)$ & $3.48( \pm 3.31)$ & 1.935 \\
FDA & $12.12( \pm 4.64)$ & $11.04( \pm 5.27)$ & 0.851 \\
DA & $12.53( \pm 3.40)$ & $12.15( \pm 4.01)$ & 0.402 \\
TVcom & $12.38( \pm 1.23)$ & $11.44( \pm 2.68)$ & 1.683 \\
\hline
\end{tabular}

${ }^{*} p<0.05$. ECI: elderly without cognitive impairment, aMCI: amnestic mild cognitive impairment, SCL: subjective competence of cognition and language, R\&W: reading and writing, ULI: usage and learning of internet, FDA: familiar daily activity, DA: drinking alcohol, TVcom: TV comprehension

는 점수가 낮을수록 인지 활동의 어려움이 증가하는 것을 의미 한다. 위 결과에 근거하여 작성된 SCC-GC 최종본은 Appen$\operatorname{dix}$ 에 제시되어 있다.

\section{SCC-GC 총점 및 하위 영역별 수행 비교}

$\mathrm{SCC}-\mathrm{GC}$ 의 하위 영역별 평균 점수는 두 군 간 유의한 차이 를 보이지 않았으나, 전체 총점에서 군 간 유의한 차이를 보였 다 $(t=-2.637, p<0.05) . \mathrm{MCI}$ 가 $\mathrm{ECI}$ 군보다 평균 8.13 정도 낮 은 것으로 나타났다(Table 3).

\section{$\mathrm{ROC}$ 분석 결과}

외적 타당도를 검증하기 위해 $\mathrm{SCC}-\mathrm{GC}$ 의 총점을 토대로 두 군을 변별해 줄 수 있는 절단점을 산정하였다. $\mathrm{ROC}$ 분석 결과 절단점 60 을 기준으로 민감도는 $72.05 \%$, 특이도는 $61.15 \%$ 인 것 으로 나타났고, 선 아래 영역은 0.702였다(Figure 2).

\section{검사-재검사 신뢰도}

전체 피험자 61 명 중 $20 \%$ 에 해당하는 12 명을 대상으로 2주 


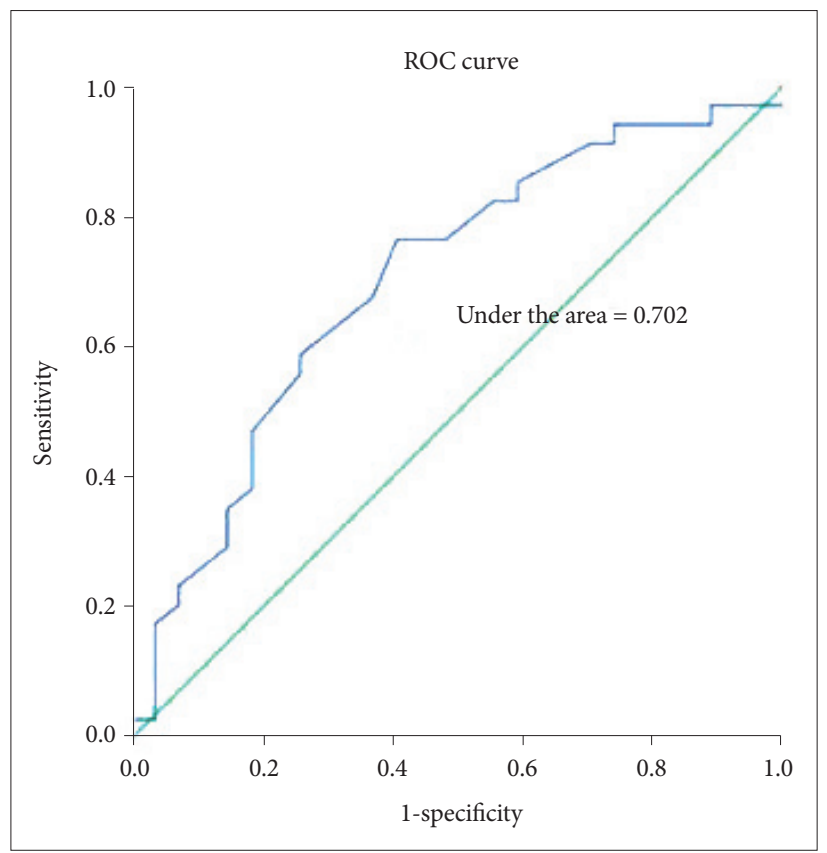

Figure 2. The ROC curve. ROC: receiver operating characteristic.

Table 4. Correlation coefficient between the SCC-GC and other measures

\begin{tabular}{lccc}
\hline Measures & K-MMSE & SVLT-E & SGDS \\
\hline SCC-GC & $0.579^{* * *}$ & $0.443^{* * *}$ & $-0.409^{* *}$ \\
\hline
\end{tabular}

${ }^{* *} p<0.01,{ }^{* * *} p<0.001$. SCC-GC: subjective checklist measuring change in global cognition, K-MMSE: Korean-mini mental status examination, SVLT-E: Seoul verbal learning test-elderly's version, SGDS: short version of the geriatric depression scale

간격을 두고 $\mathrm{SCC}-\mathrm{GC}$ 를 실시하였다. 검사-재검사 신뢰도는 $91.1 \%$ 로 적절한 것으로 나타났다.

\section{수렴 타당도}

공인된 기억검사 및 우울척도, 전반적인 정신 상태 수행력과 SCC-GC 총점 간 상관성을 살펴본 결과(Table 4), 0.409 0.579 의 범위에서 공인 검사 수행력과 새로이 개발된 SCC-GC 간의 적절한(moderate) 상관성이 관찰되었다.

\section{DISCUSSIONS}

$\mathrm{MCI}$ 환자는 치매의 임상 진단 기준에 부합하지는 않기 때문 에 치매로 진단해서는 안 되지만, 수년 안에 치매로 발전될 가 능성이 높은 집단이므로 치매와 연관하여 연구되고 언급할 필 요가 있다(Korea Dementia Association, 2011). 최근 연구에서 $\mathrm{MCI}$ 환자들은 전반적 인지, 발화, 지남력, 주의력, 집행기능, 추 상적 사고, 복합적인 시공간 인지능력 등의 다양한 인지 영역에 서 손상이 있는 것으로 보고되고 있다(Han et al., 2012; Hus- sain, 2007). 또한 퇴행성이면서 불가역적이라는 특성을 동시에 갖고 있는 $\mathrm{AD}$ 치매의 특성상 인지재활의 조기 중재가 치매 단 계에서 점차 $\mathrm{MCI}$ 환자와 같이 선행단계의 환자들로 이동하고 있다. 따라서 지역사회 내에서 이들을 조기 발견하고, 주기적으 로 관리할 수 있는 추적검사 형태의 진단/선별 도구의 필요성 은 나날이 커지고 있다. 그러나 노인의 인지능력과 특정 요인 (예: 여가활동 시간, 교육 연수, 음주량 등) 간의 상관성은 자주 언급되어 왔음에도 불구하고, 여러 요인들이 현재 노인의 인지 능력 정도를 결정하는 데 있어 어느 정도의 비중을 갖고 있고, 긍정적 또는 부정적으로 영향을 미치는지에 대해 종합적으로 파악하고자 한 시도는 드문 편이다.

종단 및 횡단 연구를 통해 보고된 바로는 객관적인 인지검사 상에서의 수행력과 주관적 기억 불만 간에 일관된 상관관계가 성립되어 있지 않은 것으로 나타난다(Christensen et al., 1991; Dufouil et al., 2005; Frerichs \& Tuokko, 2006; Jungwirth et al., 2004). 즉, 주관적 기억장애를 호소하더라도 객관적인 인지 검사상 문제가 없는 것으로 나타날 수도 있고, 객관적인 인지 장애가 관찰되더라도 주관적으로는 아무런 호소를 하지 않을 수도 있다는 것이다. 이렇게 주관적 보고와 객관적 검사 결과 간의 불일치 또는 차이(discrepancy)가 존재함에도 불구하고 본 연구에서 새로이 확립한 SCC-GC 척도가 $\mathrm{K}-\mathrm{MMSE}, \mathrm{SV}-$ LT-E와 같은 전반적인 인지 상태 및 기억능력에 대한 객관적 인 수행 결과와도 유의한 상관관계를 보여 인지 변화를 선별하 도록 설계된 정보 제공자 기반 척도의 유효성을 입증하였다. 즉, $\mathrm{SCC}-\mathrm{GC}$ 척도상 총점이 높아질수록 기억력과 전반적인 정신 상태가 높아지며, 우울감이 낮아지는 것으로 나타나 일상생활 에서의 활동과 변화 정도를 설문 형태로 체크하는 것만으로도 기억력과 우울감, 전반적인 정신 상태에 대한 추적관찰이 가능 할 수 있음을 시사한다.

본 연구를 통해 정립된 SCC-GC 척도는 객관적으로 측정되 는 수치라기보다는 보호자의 주관적 판단이 개입된다는 점에 서 주관적 보고의 특성을 내포하고 있다. 따라서 이때에는 반응 의 일관성이 매우 중요한데, SCC-GC 총점과 하위 요소(= 영 역) 간의 크론바흐 알파계수가 0.691로 산출되어 같은 개념을 다양한 하위 문항을 통해 일관성 있게 측정해 낼 수 있음을 확 인하였다. 또한 이 도구를 사용하여 $\mathrm{MCI}$ 노인의 $72.05 \%$ 가 정 확하게 선별될 수 있는 것으로 나타나 기존에 사용하는 간단/ 선별형 인지검사 후 보충적 정보를 얻기 위해, 그리고 치매가 없더라도 현재의 인지 상태를 점검하거나, 짧은 기간 단위로 노 인들의 인지 상태 변화를 추적할 때 보충적 자료로 잘 사용될 수 있음을 확인하였다. 다만, SCC-GC 척도 내 하위 영역별 평 균 비교에서는 두 군 간 유의한 차이가 없고 총점에서만 차이 를 보였으므로 추후 본 도구를 사용할 때에는 하위 영역별로 
문항을 선별적으로 선택하여 실시하지 말고, 전체 총점으로 사 용되어야만 변별력을 확보할 수 있음을 알 수 있다. 이는 SCC$\mathrm{GC}$ 척도의 하위 영역별 문항 구성 비율을 살펴봄으로써 그 이 유를 파악할 수 있는데, 각 영역을 구성하고 있는 문항의 수가 최소 1 개부터 최대 3 개까지 차이가 있었으므로 1 개 문항을 갖 고 있는 하위 영역에 대한 군 간 평균 점수 비교는 경미한 인지 장애를 갖고 있는 집단을 변별하는 데 있어 통계적인 의미를 확 보하기가 어려운 것으로 사료된다. 이는 전반적인 정신 상태를 알아보기 위해 전 세계적으로 널리 사용되고 있는 MMSE의 경우에도 하위 인지 영역을 별도로 구분하여 실시한 후 결과 를 해석할 수 없고, 총점 방식으로 피험자의 인지 저하 유무와 정도를 파악할 수 있는 점을 고려해 본다면 그와 유사한 맥락 에서 해석해 볼 수 있다.

표준화계수 베타( $\beta$ ) 값을 통해 각 요인들의 상대적인 영향력 을 비교한 결과에서 음주 영역은 주관적 인지 및 언어, 읽기/쓰 기, 인터넷 사용과 배움, 익숙한 일, TV 이해 영역에 비해 전반적 인 인지능력에 미치는 영향력이 더 큰 것으로 나타났다. 세부적 으로는 술을 전혀 마시지 않는 생활습관보다는 반주의 형태로 일상적인 섭취를 하는 생활습관이 인지능력을 유지하는 데 더 도움이 되는 것으로 관찰되었다.

알코올 섭취량과 노인의 인지능력 간의 관계를 연구한 문헌 들은 그동안 자주 보고되어 왔다. 기준 노인군을 알코올 섭취량 에 따라 알코올 비섭취군, 경도 섭취군(한 달에 1 회 이하), 중도 섭취군(한 달에 3회 이상), 심도 섭취군(매일)으로 나눈 후 7년 간의 종단연구를 통해 간이정신상태검사, 주의집중력검사, 학습 및 이름대기 검사상에서의 변화를 살펴본 Ganguli et al.(2005) 의 연구에서는 경도 및 중도 섭취군이 인지적 감퇴가 가장 적다 고 보고하면서, 이 결과가 알코올 섭취를 권장하는 것은 아니지 만 적절한 수준의 알코올 섭취는 인지능력 유지에 더 효과적이 라고 언급하였다. 좀 더 최근 연구에서도 65 세 이상 노인의 경 우 일주일에 5 7일 정도, 하루에 2잔 이내로 알코올을 섭취하 는 중고도 알코올 섭취군이 알코올 비섭취군에 비해 인지장애 발생 위험이 낮다고 보고하면서 노화 과정에서 적당한 알코올 섭취는 인지적 체력을 유지하는 건강한 생활 양식의 일부가 될 수 있음을 언급하였다(Richard et al., 2017). 각 연구마다 알코올 섭취량을 나누는 기준이 다양하고 이질적이기는 하나 인지장애 발생 위험을 낮추고, 낮은 사망률(Grønbœk et al., 2004) 및 심 혈관질환의 잠재적 예방 효과(Knoops et al., 2004)가 지속적으 로 보고되고 있는 점을 고려해 본다면, 노인의 일상생활에서 적 절한 수준의 알코올 섭취는 전반적인 인지 상태를 유지하고, 기 억력과 우울감 등에도 긍정적인 상관을 갖는 것으로 보인다.

일반적으로 검사 대상자의 인지장애 확인을 위해 정보 제공 자 기반 설문지를 사용하는 목적은 검사 대상자의 낮은 교육
수준이나 문해력으로 인해 인지검사 실시가 어렵기 때문이다. 그러나 이러한 도구들은 정보 제공자의 우울이나 불안감 등의 개인 특성에 의해 영향을 받는 것으로 보고된다(Jorm, 2004). 따라서 향후 연구에서는 SCC-GC 척도 총점에 영향을 미치는 정보 제공자 변수를 조사하는 작업이 이루어지면 고무적일 것 으로 사료된다. 또한 손상된 인지 영역이 둘 이상인 다영역 기 억성 경도인지장애는 알츠하이머형 치매로 진행될 확률이 높 은 것으로 알려져 있으므로(Han et al., 2012) 지역사회 선별보 다는 병원으로 내원하여 진단받게 되는 다영역 기억성 경도인 지장애 노인의 진전 양상을 추적관찰하기 위한 척도로도 본 연 구에서 개발된 SCC-GC 척도를 활용하여 적용 대상을 더 확 대시킬 필요가 있다.

본 연구의 제한점으로는, 좀 더 광범위한 지역과 여러 연령층 에 걸친 모집단을 설정하고 추가적인 샘플링을 실시함으로써 척 도 내 하위 영역 수행력 간의 신뢰도와 타당도를 좀 더 공고히 할 필요가 있다는 것이다. 또한 정상 노인에게서 관찰될 수 있는 본인의 현재 상태에 대한 민감한 보고나 $\mathrm{MCI}$ 환자들에게서 종 종 관찰되는 자신의 현재 인지장애에 대한 과소평가적 양상을 (Schinka et al., 2009) 보호자 보고와 본인 보고 간에 비교해 봄으로써 그 변별적 차이의 유무를 확인할 수 있을 것이다.

이 밖에도 누구나 편하게 사용할 수 있도록 추후 모바일 검 사가 가능한 프로토타입의 디자인 설계 후 지필검사와 동등한 효력을 지니는지에 대한 검증 및 전문적인 사용성 평가가 필요 하다. 추가적으로 노인의 어플리케이션 활용 동기와 흥미 유발 을 고취시키기 위해 인지 변화를 파악하는 일상생활 활동 패턴 조사뿐만 아니라 엔터테인먼트, 인지훈련 차원의 추가 콘텐츠 개발도 함께 이루어진다면 지역사회 내 인지장애 고위험군을 조기에 판별해 냄과 동시에 중재 목적의 유용한 도구로써 활용 될 수 있을 것이라 기대한다.

중심 단어 : 기억성 경도인지장애·인지·노인·주관적 체크리스트.

\section{Ethical Statement}

We explained exactly the purpose and process of this study to all participants in advance. And they agreed to participate in it. This study was approved by the Institutional Review Board (IRB\#: 1040621-201807-HR012-02).

\section{Acknowledgments}

The authors thank to the participants.

\section{Declaration of Conflicting Interests}

There are no conflict of interests.

\section{Funding}

N/A

\section{Author Contributions}

All authors contributed equally to this work. E.J. designed and per- 
formed experiments, analyzed data wrote the paper; E.J. performed experiments in the community senior center; J.K. designed experiments and provided statistical analysis, critical revision. Also, the authors discussed the results together and implications and commented on the manuscript at each stage.

\section{ORCID iDs}

Eunkyung Jeong JungWan Kim

https://orcid.org/0000-0002-2938-3274

https://orcid.org/0000-0003-3763-0914

\section{REFERENCES}

American Psychiatric Association. (2013). Diagnostic and Statistical Manual of Mental Disorders. (5th ed.). Arlington, VA: American Psychiatric Publishing.

Belleville, S., Clément, F., Mellah, S., Gilbert, B., Fontaine, F., \& Gauthier, S. (2011). Training-related brain plasticity in subjects at risk of developing Alzheimer's disease. Brain, 134(6), 1623-1634.

Buelow, M. T., Tremont, G., Frakey, L. L., Grace, J., \& Ott, B. R. (2014). Utility of the cognitive difficulties scale and association with objective test performance. American Journal of Alzheimer's Disease and Other Dementias, 29(8), 755-761.

Christensen, K. J., Multhaup, K. S., Nordstrom, S., \& Voss, K. (1991). A cognitive battery for dementia: Development and measurement characteristics. Psychological Assessment: A Journal of Consulting and Clinical Psychology, 3(2), 168-174.

Clare, L., Marková, I. S., Roth, I., \& Morris, R. G. (2011). Awareness in Alzheimer's disease and associated dementias: Theoretical framework and clinical implications. Aging and Mental Health, 15(8), 936-944.

Cooper, C., Li, R., Lyketsos, C., \& Livingston, G. (2013). Treatment for mild cognitive impairment: Systematic review. The British Journal of Psychiatry, 203(3), 255-264.

Dufouil, C., Fuhrer, R., \& Alpérovitch, A. (2005). Subjective cognitive complaint and cognitive decline: Consequence or predictor? The Epidemiology of Vascular Aging Study. Journal of the American Geriatrics Society, 53(4), 616-621.

Farias, S. T., Mungas, D., Reed, B. R., Cahn-Weiner, D., Jagust, W., Baynes, K., et al. (2008). The measurement of everyday cognition (ECog): Scale development and psychometric properties. Neuropsychology, 22(4), 531-544.

Fratiglioni, L., Paillard-Borg, S., \& Winblad, B. (2004). An active and socially integrated lifestyle in late life might protect against dementia. The Lancet Neurology, 3(6), 343-353.

Frerichs, R. J. \& Tuokko, H. A. (2006). Reliable change scores and their relation to perceived change in memory: Implications for the diagnosis of mild cognitive impairment. Archives of Clinical Neuropsychology, 21(1), 109-115.

Fyock, C. A. \& Hampstead, B. M. (2015). Comparing the relationship between subjective memory complaints, objective memory performance, and medial temporal lobe volumes in patients with mild cognitive impairment. Alzheimer's and Dementia: Diagnosis, Assessment and Disease Monitoring, 1(2), 242-248.

Galvin, J. E., Roe, C. M., Xiong, C., \& Morris, J. C. (2006). Validity and reliability of the AD8 informant interview in dementia. Neurology, 67(11), 1942-1948.

Ganguli, M., Vander Bilt, J., Saxton, J. A., Shen, C., \& Dodge, H. H. (2005). Alcohol consumption and cognitive function in late life: A longitudinal community study. Neurology, 65(8), 1210-1217.

Gavett, R. A., Dunn, J. E., Stoddard, A., Harty, B., \& Weintraub, S. (2011). The Cognitive Change in Women Study (CCW): Informant ratings of cognitive change but not self ratings are associated with neuropsychological performance over three years. Alzheimer Disease and Associated Disorders, 25(4), 305-311.

Grønbœe, M., Johansen, D., Becker, U., Ole Hein, H., Schnohr, P., Jensen,
G., et al. (2004). Changes in alcohol intake and mortality: A longitudinal population-based study. Epidemiology, 15(2), 222-228.

Han, E. Y., Han, H. J., Kim, H., Kim, B. R., \& Im, S. H. (2012). Therapeutic exercise strategies in patients with dementia. Dementia and Neurocognitive Disorders, 11(4), 118-123.

Hughes, C. P., Berg, L., Danziger, W. L., Coben, L. A., \& Martin, R. L. (1982). A new clinical scale for the staging of dementia. The British Journal of Psychiatry, 140(6), 566-572.

Hussain, H. (2007). Restriction in complex activities of daily living in MCI: Impact on outcome. Neurology, 68(18), 1544-1545; author reply 1545.

Isella, V., Villa, L., Russo, A., Regazzoni, R., Ferrarese, C., \& Appollonio, I. M. (2006). Discriminative and predictive power of an informant report in mild cognitive impairment. Journal of Neurology, Neurosurgery, and Psychiatry, 77(2), 166-171.

Jorm, A. F. (1994). A short form of the informant questionnaire on cognitive decline in the elderly (IQCODE): Development and cross-validation. Psychological Medicine, 24(1), 145-153.

Jorm, A. F. (2004). The informant questionnaire on cognitive decline in the elderly (IQCODE): A review. International Psychogeriatrics, 16(3), 275293.

Jung, I. K., Kwak, D. I., Joe, S. H., \& Lee, H. S. (1997). A study of standardization of Korean form of geriatric depression scale (KGDS). Journal of Korean Geriatric Psychiatry, 1(1), 61-72.

Jungwirth, S., Fischer, P., Weissgram, S., Kirchmeyr, W., Bauer, P., \& Tragl, K. H. (2004). Subjective memory complaints and objective memory impairment in the Vienna-Transdanube Aging community. Journal of the American Geriatrics Society, 52(2), 263-268.

Kang, Y. (2006). A normative study of the Korean-mini mental state examination (K-MMSE) in the elderly. Korean Journal of Psychology, 25(2), $1-12$.

Kang, Y. \& Na, D. L. (2003). Seoul Verbal Learning Test. In Kang, Y. \& Na, D. L. Seoul Neuropsychological Screening Battery (SNSB). Seoul: Human Brain Research \& Consulting Co.

Knoops, K. T. B., de Groot, L. C. P. G. M., Kromhout, D., Perrin, A. E., Moreiras-Varela, O., Menotti, A., et al. (2004). Mediterranean diet, lifestyle factors, and 10-year mortality in elderly European men and women: The HALE project. The Journal of the American Medical Association, 292(12), 1433-1439.

Korea Dementia Association. (2011). Dementia a Cilinical Approach. Anyang: Academya.

Lee, M. S. (2015). Meta-analysis of correlation between subjective and objective cognitive-linguistic tests: Focused on normal aging, MCI, and dementia. Journal of the Korea Academia-Industrial Cooperation Society, 16(11), 7414-7423.

Lee, M. S. \& Kim, B. S. (2020). A preliminary study for the development of informant-report scale on cognitive-linguistic abilities of the elderly: Focused on mild cognitive impairment and Alzheimer's disease. Audiology Speech and Research, 16(2), 167-174.

McKhann, G., Drachman, D., Folstein, M., Katzman, R., Price, D., \& Stadlan, E. M. (1984). Clinical diagnosis of Alzheimer's disease: Report of the NINCDS-ADRDA Work Group under the auspices of Department of Health and Human Services Task Force on Alzheimer's disease. Neurology, 34(7), 939-944.

Paillard-Borg, S., Fratiglioni, L., Xu, W., Winblad, B., \& Wang, H. X. (2012). An active lifestyle postpones dementia onset by more than one year in very old adults. Journal of Alzheimer's Disease, 31(4), 835-842.

Petersen, R. C., Doody, R., Kurz, A., Mohs, R. C., Morris, J. C., Rabins, P. V., et al. (2001). Current concepts in mild cognitive impairment. Archives of Neurology, 58(12), 1985-1992.

Petersen, R. C. (2003). Mild Cognitive Impairment: Aging to Alzheimer's Disease. (pp. 1-14). New York, NY: Oxford University Press.

Petersen, R. C. (2004). Mild cognitive impairment as a diagnostic entity. Journal of Internal Medicine, 256(3), 183-194.

Richard, E. L., Kritz-Silverstein, D., Laughlin, G. A., Fung, T. T., BarrettConnor, E., \& McEvoy, L. K. (2017). Alcohol intake and cognitively 
healthy longevity in community-dwelling adults: The Rancho Bernardo Study. Journal of Alzheimer's Disease, 59(3), 803-814.

Schinka, J. A., Brown, L. M., \& Proctor-Weber, Z. (2009). Measuring change in everyday cognition: Development and initial validation of the cognitive change checklist (3CL). The American Journal of Geriatric Psychiatry, 17(6), 516-525.

Song, J. J. (2015). SPSS/AMOS Statistical Analysis Method Required for The- sis Preparation. Paju: 21C book.

Storandt, M., Grant, E. A., Miller, J. P., \& Morris, J. C. (2006). Longitudinal course and neuropathologic outcomes in original vs revised MCI and in pre-MCI. Neurology, 67(3), 467-473.

Won, C. W., Rho, Y. G., Woo, D. S., \& Lee, Y. S. (2002). The validity and reliability of Korean instrumental activities of daily living (K-IADL) scale. Journal of the Korean Geriatrics Society, 6(4), 273-280. 


\section{APPENDIX $\square$}

\section{전반적 인지 변화를 측정하는 주관적 체크리스트 (Subjective Checklist Measuring Change in Global Cognition, SCC-GC)}

\section{지시 사항: 지난 한 달 동안 당신은?}

\begin{tabular}{|c|c|c|c|c|}
\hline \multicolumn{5}{|c|}{ 당신의 인지 및 언어 능력은 어디에 위치한다고 생각하시나요? } \\
\hline (1) 매우 안 좋음(0) & (2) 약간 안 좋음(5) & (3) 보통(10) & (4) 좋음(15) & (5) 매우 좋음(20) \\
\hline \multicolumn{3}{|r|}{ 주관적 인지 및 언어 } & \multicolumn{2}{|r|}{$/ 20$} \\
\hline \multicolumn{5}{|c|}{ 책이나 신문 등 정보를 얻을 수 있는 글을 읽으셨나요? } \\
\hline (1) 전혀 안 읽음(2) & (2) 아주 가끔 읽음(4) & (3) 가끔 읽음(6) & (4) 자주 읽음(8) & (5) 매우 자주 읽음(10) \\
\hline \multicolumn{5}{|c|}{ 달력이나 수첩 등에 해야 할 일이나 중요한 내용을 정리하셨나요? } \\
\hline (1) 전혀 안 함(2) & (2) 아주 가끔 함(4) & (3) 가끔 함(6) & (4) 자주 함(8) & (5) 매우 자주 함(10) \\
\hline \multicolumn{3}{|r|}{ 읽기/쓰기 } & \multicolumn{2}{|r|}{$/ 20$} \\
\hline \multicolumn{3}{|l|}{ 인터넷을 사용하시나요? } & (1) 예(2) & (2) 아니오(0) \\
\hline \multicolumn{5}{|c|}{ 문자 메시지나 SNS(예: 카카오톡, 카카오 스토리 등)를 통해서 메시지를 남기셨나요? } \\
\hline (1) 전혀 안 함(2) & (2) 아주 가끔 함(4) & (3) 가끔 함(6) & (4) 자주 함(8) & (5) 매우 자주 함(10) \\
\hline \multicolumn{3}{|c|}{ 외국어나 스포츠, 취미·교양 등에서 새로 배우는 일이 있었나요? } & (1) 안 배움(0) & (2) 배움(4) \\
\hline & & 인터넷 사용과 배움 & \multicolumn{2}{|r|}{$/ 16$} \\
\hline \multicolumn{5}{|c|}{ 집안에 필요한 식료품이나 생필품을 누가 확인하고 구매하였나요? } \\
\hline $\begin{array}{c}\text { (1) 전적으로 } \\
\text { 다른 사람이 관리(1) }\end{array}$ & $\begin{array}{c}\text { (2) 거의 다 } \\
\text { 도움을 받아 관리(2) }\end{array}$ & $\begin{array}{c}\text { (3) 절반 정도 } \\
\text { 도움을 받아 관리(3) }\end{array}$ & $\begin{array}{c}\text { (4) 약간 } \\
\text { 도움을 받아 관리(4) }\end{array}$ & (5) 혼자 관리(5) \\
\hline \multicolumn{5}{|c|}{ 집안에서 누가 식사를 준비하였나요? } \\
\hline $\begin{array}{c}\text { (1) 전적으로 } \\
\text { 다른 사람이 준비(1) }\end{array}$ & $\begin{array}{c}\text { (2) 거의 다 } \\
\text { 도움을 받음(2) }\end{array}$ & $\begin{array}{l}\text { (3) 절반 정도 } \\
\text { 도움을 받음(3) }\end{array}$ & $\begin{array}{c}\text { (4) 약간 } \\
\text { 도움을 받음(4) }\end{array}$ & (5) 혼자 준비(5) \\
\hline \multicolumn{5}{|c|}{ 공과금 납부와 예·적금 등의 가정 내 가계를 누가 관리하였나요? } \\
\hline $\begin{array}{l}\text { (1) 다른 사람이 } \\
\text { 관리(1) }\end{array}$ & $\begin{array}{c}\text { (2) 전부 } \\
\text { 도움을 받아 관리(2) }\end{array}$ & $\begin{array}{c}\text { (3) 대부분 } \\
\text { 도움을 받아 관리(3) }\end{array}$ & $\begin{array}{c}\text { (4) 일정 부분 } \\
\text { 도움을 받아 관리(4) }\end{array}$ & (5) 혼자 관리(5) \\
\hline & & 집안일 & \multicolumn{2}{|c|}{$\begin{array}{rr}/ 16 \\
\text { \#(문항 상관없이 기본 1점 있음) }\end{array}$} \\
\hline \multicolumn{2}{|l|}{ 술을 얼마나 드셨나요? } & (1) 음주 안 함(1) & (2) 가끔 마심(8) & (3) 매일 마심(15) \\
\hline & & 음주 & \multicolumn{2}{|r|}{$/ 15$} \\
\hline \multicolumn{5}{|c|}{ TV를 보며 내용을 이해하셨나요? } \\
\hline $\begin{array}{c}\text { (1) 전혀 } \\
\text { 이해하지 못함(1) }\end{array}$ & $\begin{array}{c}\text { (2) 거의 } \\
\text { 이해하지 못함(4) }\end{array}$ & (3) 보통(7) & (4) 거의 대부분 이해(10) & (5) 완전히 이해(13) \\
\hline \multicolumn{3}{|r|}{ TV 내용 이해 } & \multicolumn{2}{|r|}{$/ 13$} \\
\hline \multicolumn{3}{|c|}{ Total score } & \multicolumn{2}{|r|}{$/ 100$} \\
\hline
\end{tabular}

